\title{
Hypodontia and WNT10A mutation: a case report
}

\author{
Marija Živković Sandić ${ }^{1}$ Neda Stefanović ${ }^{1}$, Branka Popović2 ${ }^{2}$ Branislav Glišić ${ }^{1}$ \\ 'University of Belgrade, Faculty of Dental Medicine, Department for Orthodontics, Belgrade, Serbia; \\ ${ }^{2}$ Institute of Human Genetics, University of Belgrade, Faculty of Dental Medicine, Belgrade, Serbia
}

\begin{abstract}
SUMMARY
Tooth agenesis is common dentofacial malformation in humans. Its etiology is still not clear. Hypodontia has been regarded as a multifactorial condition influenced by gene function, environmental interaction and developmental timing. More than 300 genes have been related with patterning, morphogenesis and cell differentiation in teeth. According to data WNT10A gene is considered to have an important role in odontogonesis.

The aim of this study was to show mutation status in WNT10A gene in a family with two members with diagnosis of hypodontia/oligodontia. In the reported family (father, mother, son, daughter) children were diagnosed with congenital tooth agenesis (son-2 teeth, daughter-11 teeth), while parents negated congenital absence of teeth. We identified a heterozygous missense mutation, c.682T>A ( .Phe228lle) within the exon 3 of WNT10A in mother and father and the same homozygous mutation was detected in the same region of WNT10A gene in daughter and son. Observed differences in our study, from no symptoms to mild/severe hypodontia, could be the consequence of genetic influence of c.682T >A(p.Phe228lle) mutation, but also the contribution of many environmental factors during odontogenesis.

Keywords: hypodontia/ oligodontia; homozygous; heterozygous; mutation; WNT10A gene
\end{abstract}

\section{INTRODUCTION}

Tooth agenesis is common dentofacial malformation in humans [1]. It can occur either as an isolated characteristic (non-syndromic form) or as a part of recognized clinical syndrome [2]. Different terms are used to describe this anomaly, depending on the number of congenitally missing teeth. Hypodontia is used when one to six teeth (excluding third molars) are congenitally missing, while oligodontia means that more than six teeth are missing (excluding third molars). Term anodontia is used for extreme case of complete absence of teeth [3].

The etiology of tooth agenesis is still not clear. Hypodontia has been regarded as a multifactorial condition influenced by gene function, environmental interaction and developmental timing $[4,5]$.

More than 300 genes have been related with patterning, morphogenesis and cell differentiation in teeth so far [6]. Tooth agenesis can be the result of different nucleotide changes in genes that are involved in the process of tooth formation. Their products are signal molecules and transcription factors that control gene expression in different phases of tooth morphogenesis. According to data, WNT10A is one of the most important candidate genes expressed in epithelial cells and through Wnt/B-catenin signal pathway its signal protein may activate mesenchymal cells during early phase of odontogenesis. Moreover, WNT10A mutations can be possible cause of tooth agenesis in affected individual [6-9].

The aim of this study was to present detected mutations in the WNT10A gene in a family where two members were affected by congenital tooth agenesis.

\section{CASE REPORT}

A Serbian family (mother, father, son and daughter) presented two members (son and daughter) with diagnosis of congenital tooth agenesis. Panoramic radiographs and clinical examination confirmed hypo/oligodontia. All family members were examined for other symptoms of ectodermal dysplasia but none was detected. No panoramic radiographs were available for the parents, however they denied congenital absence of any teeth in a detailed interview. The daughter was diagnosed with oligodontia - 11 teeth congenitally missing (upper lateral incisors, upper second molars, lower central and lateral incisors, lower canines, and lower left second molar), while the son was diagnosed with hypodontia of lower central incisors. Panoramic radiographs and odontograms of the daughter and the son are shown in the Figure 1.

\section{Mutational analysis}

Informed consent was obtained from the patients and the Human Research Ethics Committee of the Faculty of Dental Medicine, University of Belgrade, approved the study. Buccal swabs from family members were used to obtain DNA, and WNT10A mutational analysis of "hot spot" regions, exon 2 and 3, was performed by method of direct sequencing. Heterozygous missense mutation, c.682T $>\mathrm{A}$, within the exon 3 of WNT10A in mother and father (I-1 and I-2) and homozygous mutation in the same region of WNT10A gene in daughter and son (II-1 and II-2) were detected. Reported mutation lead to amino-acid exchange, p.Phe228Ile, that had pathological effect (Table 1, Figure 2). 


\section{8) 8081803680 .

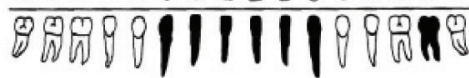

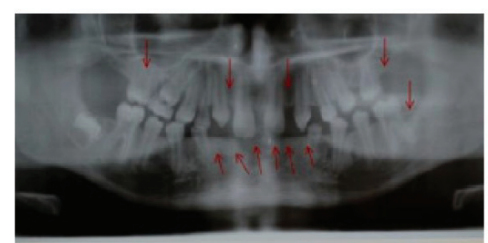

a) DAUGHTER(II-1)
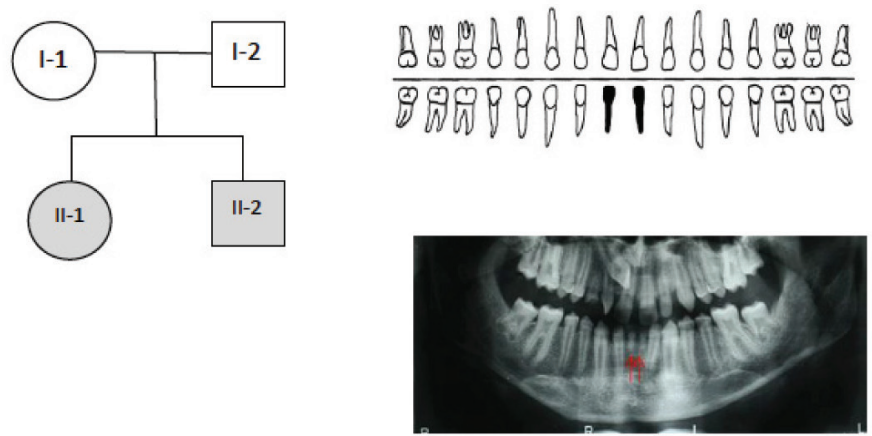

b) SON(II-2)

Figure 1. Heredity of the family

Panoramic radiographs and odontograms of daughter and son

a) Oligodontia (daughter) - 11 congenitally missing teeth, b) Hypodontia (son) - 2 congenitally missing teeth

Slika 1. Rodoslovno stablo

Ortopantomografski snimci ćerke i sina i odontogrami

a) Oligodoncija (ćerka) - urođeni nedostatak 11 stalnih zuba, b) Hipodoncija (sin) - urođeni nedostatak dva zuba

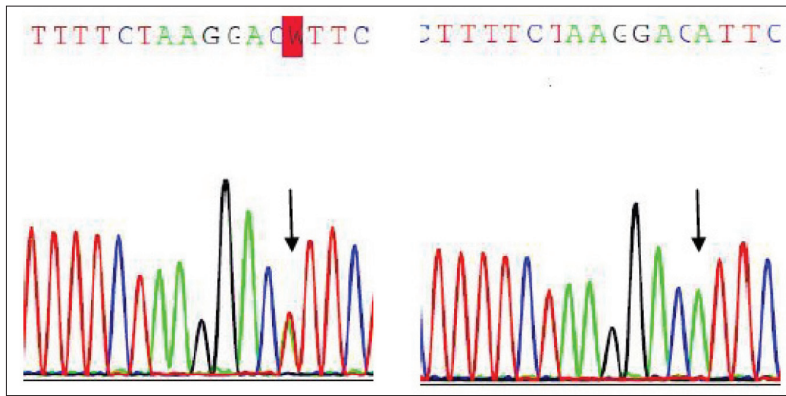

Figure 2. Missense WNT10A mutation (rs121908120) c.682T> A[TTT $\rightarrow$ ATT] p.Phe228lle a) TA* (heterozygous mutation), b) $A^{*} A^{*}$ (homozygous mutation)

Slika 2. "Missense" mutacija gena WNT10A (rs121908120) c.682T >A[TTT $\rightarrow$ ATT] p.Phe228lle

a) TA* (heterozigotna mutacija), b) $A^{*} A^{*}$ (homozigotna mutacija)

\section{DISCUSSION}

The reported Serbian family had no manifestations of ectodermal dysplasia. Missense mutation c.682T $>\mathrm{A}$ (p.Phe228Ile) within the exon 3 of WNT10A gene was detected in all members of the family, in heterozygous or homozygous form. In our case report family, the pattern of inheritance probably could be autosomal recessive or autosomal dominant with different gene penetrance, since there was no data of parents' congenitally missing teeth. Kantaputra and Sripathomsawat found the same mutation in a family with non-syndromic hypodontia and without other changes in ectodermal tissues [9]. They also detected a c.682T $>$ A mutation for the father (missing maxillary first premolars) and two sons (one had missing upper lateral incisors and lower second premolars, and the other one presented with microdontia of the lower left second premolar). The mother did not have mentioned mutation, and she was not affected with hypodontia. Interestingly, the mother had p.Asp217Asn mutation that was also detected in the WNT10A genes of the two sons.
Table 1. Family members with p.Phe228Ile mutation in WNT10A gene

Parents with heterozygous mutation and not affected Affected daughter and son have homozygous mutation Tabela 1. Članovi porodice sa p.Phe228lle mutacijom gena WNT10A

Roditelji sa heterozigotnom mutacijom bez promena u broju zuba Sin i ćerka sa homozigotnom mutacijom i urođenim nedostatkom zuba

\begin{tabular}{|l|c|c|c|c|}
\hline $\begin{array}{l}\text { Family } \\
\text { member } \\
\text { Član porodice }\end{array}$ & $\begin{array}{c}\text { Mother } \\
\text { Majka }\end{array}$ & $\begin{array}{c}\text { Father } \\
\text { Otac }\end{array}$ & $\begin{array}{c}\text { Daughter } \\
\text { Ćerka }\end{array}$ & $\begin{array}{c}\text { Son } \\
\text { Sin }\end{array}$ \\
\hline $\begin{array}{l}\text { Number } \\
\text { Broj }\end{array}$ & $\mathrm{I}-1$ & $\mathrm{I}-2$ & $\mathrm{II-1}$ & $\mathrm{Il-2}$ \\
\hline $\begin{array}{l}\text { Gender } \\
\text { Pol }\end{array}$ & $\mathrm{F}$ & $\mathrm{M}$ & $\mathrm{F}$ & $\mathrm{M}$ \\
\hline $\begin{array}{l}\text { Missing teeth } \\
\text { Nedostajući } \\
\text { zubi }\end{array}$ & 0 & 0 & 11 & 2 \\
\hline $\begin{array}{l}\text { Mutation } \\
\text { WNT10A } \\
\text { (p.Phe228lle) }\end{array}$ & $\begin{array}{l}\text { T/A* } \\
\text { heterozygous } \\
\text { heterozigotni }\end{array}$ & $\begin{array}{l}\text { T/A* } \\
\text { heterozygous } \\
\text { heterozigotni }\end{array}$ & $\begin{array}{l}\mathrm{A}^{*} / \mathrm{A}^{*} \\
\text { homozygous } \\
\text { homozigotni }\end{array}$ & $\begin{array}{c}\mathrm{A}^{*} / \mathrm{A}^{*} \\
\text { homozygous } \\
\text { homozigotni }\end{array}$ \\
\hline
\end{tabular}

According to these clinical observations and obtained data in our analyzed family, the mode of c.682T $>\mathrm{A}$ inheritance of WNT10A gene could probably be autosomal dominant. Moreover, in a study of Bohring at al. pathogenic mutation c.682T $>\mathrm{A}$ was detected in patients with ectodermal dysplasia and the same mutation, considered as disease causing, was found in healthy individuals $(0.5 \%)$ [10].Analyzing phenotype manifestations in patients with heterozygous mutation p.Phe228Ile, Bohring et al. also reported that heterozygotes showed minor phenotype manifestations associated with teeth (small, conical, sharp, or missing upper lateral permanent incisors; agenesis of lower right central incisor or agenesis of 2 to 6 permanent teeth except third molars), or no manifestations at al. [10].

Similarly, in our reported family, diverse clinical manifestations were reported in carriers of c.682T $>$ A WNT10A mutation (heterozygote parents and homozygote son and daughter). Observed differences in our study, from no symptoms to mild/severe hypodontia, could be the con- 
sequence of genetic influence of the suspected gene, but also the impact of many environmental factors during odontogenesis.

\section{REFERENCES}

1. Al-Ani AH, Antoun JS, Thomson WM, Merriman TR, Farella M. Hypodontia: An Update on Its Etiology, Classification, and Clinical Management. Biomed Res Int. 2017; 2017:9378325.

[DOl: 10.1155/2017/9378325] [PMID: 28401166]

2. Cobourne MT, Sharpe PT. Diseases of the tooth: the genetic and molecular basis of inherited anomalies affecting the dentition. Wiley Interdiscip Rev Dev Biol. 2013; 2(2):183-212. [DOI: 10.1002/wdev.66] [PMID: 24009033]

3. Arte S. Phenotypic and Genotypic features of Familial Hypodontia. Doctoral Thesis. Helsinki, Finland: University of Helsinki; 2001.

4. Brook AH. A unifying aetiological explanation for anomalies of human tooth number and size. Arch Oral Biol. 1984; 29:373-8. [DOI: 10.1016/0003-9969(84)90163-8] [PMID: 6611147]

5. Cobourne M. Familial human hypodontia - Is it all in the genes? Br Dent ). 2007; 203(4):203-8. [DOl: 10.1038/bdj.2007.732] [PMID: 17721480]
6. Thesleff I. The genetic basis of tooth development and dental defects. Am J Med Genet A. 2006; 140(23):2530-5. [DOI: 10.1002/ajmg.a.31360] [PMID: 16838332]

7. Vastardis H. The genetics of human tooth agenesis: New discoveries for understanding dental anomalies. Am J Orthod Dentofacial Orthop. 2000; 117(6):650-6. [DOI: 10.1067/mod.2000.103257] [PMID: 10842107]

8. Van den Boogaard MJ, Cre' ton M, Bronkhorst $Y$, van der Hout A, Hennekam E, Lindhout D, et al. Mutations in WNT10A are present in more than half of isolated hypodontia cases. J Med Genet. 2012; 49(5):327-31. [DOI: 10.1136/jmedgenet-2012-100750] [PMID: 22581971]

9. Kantaputra P, Sripathomsawat W. WNT10A and isolated hypodontia. Am J Med Genet A. 2011; 155A(5):1119-22. [DOI: 10.1002/ajmg.a.33840] [PMID: 21484994]

10. Bohring A, Stamm T, Spaich C, Haase C, Spree K, Hehr U, et al. WNT10A mutations are a frequent cause of a broad spectrum of ectodermal dysplasias with sex-biased manifestation pattern in heterozygotes. Am J Hum Genet. 2009; 85(1):97-105. [DOI: 10.1016/j.ajhg.2009.06.001] [PMID: 19559398]

Received: 29.11.2017 • Accepted: Prihvaćen 21.02.2018 


\title{
Hipodoncija i mutacija WNT10A gena: prikaz slučaja
}

\author{
Marija Živković Sandić1, Neda Stefanović1, Branka Popović2, Branislav Glišić \\ 'Univerzitet u Beogradu, Stomatološki fakultet, Klinika za ortopediju vilica, Beograd, Srbija; \\ 2Institut za humanu genetiku, Univerzitet u Beogradu, Stomatološki fakultet, Beograd, Srbija
}

\begin{abstract}
KRATAK SADRŽAJ
Urođeni nedostatak zuba predstavlja jednu od najčešćih dentofacijalnih anomalija kod čoveka. Etiologija hipodoncije i dalje nije potpuno definisana i smatra se da su za njenu etiologiju odgovorni brojni genetski i sredinski faktori koji deluju u različitim fazama razvoja zuba. Preko 300 gena povezuje se sa morfogenezom i ćelijskom diferencijacijom u toku razvoja zuba, a prema podacima WNT10A gen je jedan od gena koji ima veoma bitnu ulogu u kontroli odontogeneze. Cilj ovog rada bio je da se prikaže mutacioni status WNT10A gena u porodici sa dijagnostikovanom hipodoncijom/oligodoncijom. U prikazanoj porodici (otac, majka, sin i ćerka) kod dva člana dijagnostikovan je urođeni nedostatak zuba (sin - dva zuba, ćerka - 11 zuba), dok kod roditelja ovaj nedostatak nije zabeležen. Kod svih članova porodice, u okviru egzona 3 WNT10A gena detektovana je mutacija c.682T>A (p.Phe228lle). Kod majke i oca ova "missense“ mutacija je bila u heterozigotnom obliku, dok je kod sina i ćerke utvrđeno prisustvo iste mutacije u homozigotnom obliku. Zabeležene razlike u analiziranoj porodici, od odsustva simptoma do blage hipodoncije i izrazite oligodoncije, mogu biti posledica prisustva c.682T >A (p.Phe228lle) mutacije, ali takođe i uticaja faktora sredine u toku odontogeneze.

Ključne reči: hipodonciia/oligodoncija; homozigotni; heteroigotni; mutacija; WNT10A gen
\end{abstract}

\section{UVOD}

Urođeni nedostatak zuba predstavlja jednu od najčešćih dentofacijalnih anomalija kod čoveka [1]. Može biti izolovana (nesindromska) ili se može pojaviti u okviru nekog kliničkog sindroma [2]. U zavisnosti od broja zuba koji urođeno nedostaju, različiti termini se koriste da se opiše ova anomalija. Termin hipodoncija se koristi kada urođeno nedostaje jedan do šest zuba (isključujući treće molare), dok termin oligodoncija ukazuje da u denticiji nedostaje više od šest zuba (isključujući treće molare). Termin anodoncija se vezuje za ekstremne slučajeve kompletnog odsustva svih zuba u vilicama [3].

Etiologija hipodoncije i dalje nije potpuno definisana. Smatra se da je za etiologiju hipodoncije odgovorno više faktora : brojni genetski i sredinski faktori koji deluju u različitim fazama razvoja zuba $[4,5]$.

Kao što je već poznato, preko 300 gena se povezuje sa morfogenezom i ćelijskom diferencijacijom u toku razvoja zuba [6]. Urođeni nedostatak zuba može biti posledica različitih nukleotidnih izmena u genima uključenim u proces odontogeneze. Produkti ovih gena su signalni molekuli i transkripcioni faktori koji kontrolišu ekspresije gena u različitim fazama morfogeneze zuba. Prema podacima, WNT10A je jedan od najvažnijih gena eksprimiranih u epitelnim ćelijama, i u okviru Wnt/B-catenin signalnog puta njegov signalni protein može aktivirati mezenhimne ćelije u ranoj fazi odontogeneze. Takođe, različite mutacije WNT10A gena mogu dovesti do urođenog nedostatka zuba kod nosioca mutacije [6-9].

Cilj ovog rada bio je da se prikaže mutacioni status WNT10A gena u porodici sa dijagnostikovanom hipodoncijom/ oligodoncijom.

\section{PRIKAZ BOLESNIKA}

Prikazana je četvoročlana porodica iz Srbije (majka, otac, sin, ćerka) u kojoj je kod dva člana (sina i ćerke) dijagnostikovan urođeni nedostatak zuba. Hipo/oligodoncija je potvrđena ortopantomografskim snimcima i kliničkim pregledom. Utvrđeno je da nijedan od članova porodice nije imao druge manifestacije ektodermalne displazije. Roditelji su u anamnezi negirali postojanje urođenog nedostatka zuba jer ortopantomografski snimci nisu bili dostupni. Kod ćerke je dijagnostikovana oligodoncija urođeni nedostatak 11 zuba (gornji bočni sekutići, gornji drugi molari, donji centralni i bočni sekutići, donji očnjaci i donji drugi levi molar), dok je kod sina dijagnostikovana hipodoncija donjih centralnih sekutića. Ortopantomografski snimci ćerke i sina sa odontogramima su prikazani na Slici 1. Članovi porodice su za učešće u studiji potpisali informisani pristanak i studija je odobrena od strane Etičkog komiteta Stomatološkog fakulteta u Beogradu.

\section{MUTACIONA ANALIZA}

Za dobijanje genomske DNK korišćen je bris bukalne sluzokože. Primenom metode direktnog sekvenciranja urađena je mutaciona analiza egzona 2 i 3 WNT10A gena. Kod svih članova porodice identifikovana je ista mutacija (c.682T $>$ A, p.Phe228Ile). Tačnije, kod majke i oca (I-1 and I-2) identifikovana je heterozigotna "missense“ mutacija u okviru egzona 3 WNT10A gena, dok je kod sina i ćerke utvrđeno prisustvo iste mutacije u homozigotnom obliku (II-1 and II-2). Dobijena mutacija dovodi do amino-kiselinske izmene u WNT proteinu, p.Phe228Ile, i smatra se da ima patološki efekat (Tabela 1, Slika 2).

\section{DISKUSIJA}

Na osnovu anamnestičkih podataka, kod prikazane porodice nisu bile prisutne manifestacije ektodermalne displazije, ali je kod svih članova porodice, u heterozigotnoj ili homozigotnoj formi, detektovana "missense" mutacija, c.682T $>\mathrm{A}$ (p.Phe228Ile) u okviru egzona 3 WNT10A gena. Način nasleđivanja date mutacije u prikazanoj porodici mogao bi da bude autozomno recesivan ili autozomno dominantan sa različitom penetrantnošću gena, s obzirom na to da nema podataka o urođenom nedostatku zuba kod roditelja koji imaju mutaci- 
ju. Kao i u našoj analiziranoj porodici, u studiji Kantaputre i Sripathomsawata ista mutacija je prikazana u porodici sa nesindromskom hipodoncijom i bez drugih promena u ektodermalnim tkivima [9]. Naime, u njihovoj studiji detektovana je mutacija c.682T > A kod oca (kome nedostaju gornji prvi premolari) i kod dva sina (jednog sina sa nedostatkom gornjih bočnih sekutića i donjih drugih premolara, a kod drugog sina sa mikrodoncijom donjeg levog drugog premolara). S druge strane, u istoj porodici majka nije imala pomenutu mutaciju i nije imala urođeni nedostatak zuba. Ipak, kod majke je detektovana druga mutacija, p.Asp217Asn, koja je takođe bila prisutna i kod dva sina.

Na osnovu kliničkih podataka i mutacione analize, može se pretpostaviti da je način nasleđivanja c.682T > A mutacije WNT10A gena najverovatnije autozomno dominantan. Takođe, $\mathrm{u}$ studiji Bohringa i sar. patogena mutacija c.682T $>$ A detektovana je kod pacijenata sa ektodermalnom displazijom, a isto tako je utvrđeno njeno prisustvo i kod zdravih pojedinaca (0,5\%) [10]. Analizirajući fenotipske manifestacije kod pacijenata sa heterozigotnom mutacijom p.Phe228Ile, Bohring i sar. [10] navode da heterozigoti ili ne pokazuju nikakve promene, ili pokazuju štetne fenotipske efekte vezane za zube u manjoj ili većoj meri (mali, konični, oštri gornji bočni sekutići, ili nedostatak istih; ageneza donjeg desnog centralnog sekutića; ageneza dva do šest stalnih zuba isključujući treće molare).

Slično, i u našoj prikazanoj porodici kliničke manifestacije kod nosilaca c.682T>A WNT10A mutacije su različite (heterozigotni roditelji i homozigotni sin i ćerka). Zabeležene razlike u analiziranoj porodici, od odsustva simptoma do blage hipodoncije i izrazite oligodoncije, mogu biti posledica prisustva c.682T >A (p.Phe228Ile) mutacije, ali takođe i uticaja faktora sredine $\mathrm{u}$ toku odontogeneze. 